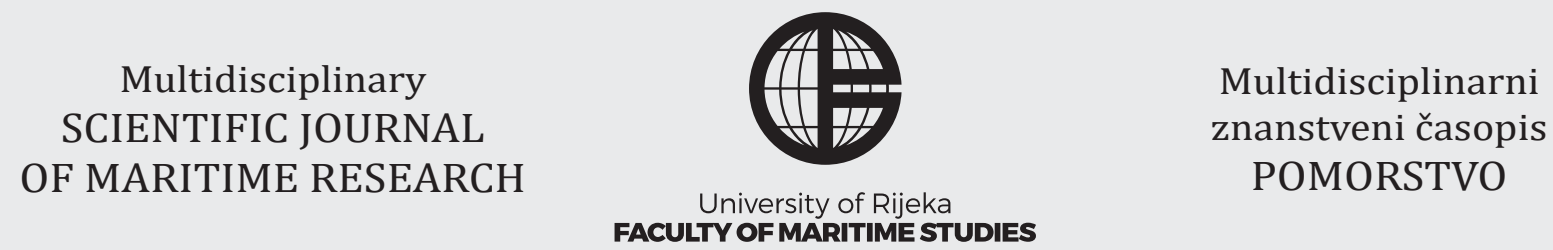

\title{
Flow visualization and analytical study on the exhaust gas diffusion of a frigate
}

\author{
Erinc Dobrucali \\ Bursa Technical University, Maritime Faculty, Department of Naval Architecture and Marine Engineering, 16310, Bursa, Turkey, \\ e-mail: erinc.dobrucali@btu.edu.tr
}

\section{ABSTRACT}

Wind tunnel flow visualization tests were conducted to analyse the efflux velocity impacts and the yaw angle on the smoke dispersion of the exhaust for a generic frigate. An analytical study was also implemented to obtain the exhaust plume trajectories. The 1/100 scale generic frigate, having a platform for helicopters on the aft of the ship, was built and employed during the experimental study. The forward and astern cruises of the frigate were considered. It is found that the plume height and the exhaust gases momentum increase with the velocity ratio. The problem of smoke nuisance was observed for the ratios with low velocity such as $\mathrm{K}=0.2$. The plume was also directed towards the helicopter platform when the yaw angles are higher than $10^{\circ}$. The experimental results are compared with the analytical solutions for three different velocity ratios. The compliance between the experimental and analytical results is found to be consistent.

\section{ARTICLE INFO}

Preliminary communication Received 25 February 2021 Accepted 28 November 2021

\author{
Key words: \\ Flow visualization \\ Efflux velocity \\ Yaw angle \\ Plume trajectory \\ Frigate \\ Exhaust plume
}

\section{Introduction}

The naval ships as the fighting platforms have become more complicated with the progress of ship technology for the last decade. Accordingly, naval ships have now more than one radar, one or two main mast including many electronic equipment on the upper deck. Furthermore, existence of complicated weapon electronics necessitates topside lead to the compatibility of electromagnetic interference problems. This further requires these electronic devices to be mounted separated. Additionally, the sophistication of today's electronic devices on the naval ships necessitates also having more than one radar with the availability of many electronic sensors/equipment to be seated on the mast while they must be mounted highest possible altitude from the deck. But, the stack heights cannot be held similar to the merchant ships. This issue may cause smoke nuisance problems or downwash of exhaust gases for naval ships.

The exhaust smoke from the ship funnel contains such emissions like $\mathrm{NO}_{\mathrm{x}} \mathrm{CO}_{2}, \mathrm{SO}_{\mathrm{x}}, \mathrm{CO}$ and $\mathrm{PM}$ which are harm- ful to the environment as well as to the health of humans. Smoke nuisance problems or downwash of exhaust gases, when they occur, might have negative impacts. Some of these kinds of consequences are the existence of hot exhaust gases going through the air conditioning and ventilation systems of the ships and also the engine intakes, disruption of the exhaust gases to the helicopter manoeuvres and also the resulting high temperature seen over the electronic equipment mounted on the upper deck. The layout of the upper deck, funnel design and the interaction with the ship superstructure must be evaluated specifically because of those reasons.

The mutual interactions among the funnel gases, the ships superstructure setup and the exhaust smoke behaviour are so crucial points within the ship building and designing. However, the applications cannot be detected or recognized beforehand during the design phases. Rather, the downwash of the exhaust gases and smoke nuisance problems take place at the later stages such as during the trials on the sea or after the delivery. In such cases, modifications requirements in the configuration become 
unavoidable. Therefore, funnel design and the exhaust dispersion issue have become critical phenomena with respect to the radar cross-section (RCS) and infrared signature (IR) due to the advancement of military technologies.

Due to the issues described above, the detection of the exhaust dispersion is crucial specifically during the design phase of the naval ships having a helicopter platform. However, the prediction and the detection of the ship funnel exhaust plume is a very complicated issue. This is because of the existence of certain parameters such as efflux velocity of smoke, turbulence magnitude, direction and velocity of the wind and layout of the upper deck.

The studies regarding the exhaust gases and their interaction with the ship superstructure can be seen in the literature dating back to 1940's when the smoke nuisance problem exhibited itself on passenger ships [1-3]. With reference to naval ships, the smoke nuisance issue continues to be one of the main research subjects. For example, Johns and Healey have simulated the case of sheared turbulent layers [4]. They conducted the simulation in stationary mode and within a wind tunnel to analyze the airflow conditions around the flight deck of the destroyer DD 963 with the help of helium bubble, smoke and also video equipment. (See, also Johns's study [5]). In Harrell's study, the experimentations of the geometric configuration impacts on the performance of the educators were investigated by way of the cold flow model tests for the exhaust gas [6]. A variety of nozzle configurations, that is, single nozzle and four nozzle designs were checked. Non-dimensional parameters directing the flow phenomena were developed from one dimensional study. The educator performance is analysed. The experimental results for the Length/Diameter (L/D) ratios less than 8 revealed that the superiority of four-nozzle configuration over the single-nozzle ones.

However, in the literature there are not enough experimental studies on the impacts of the exhaust gases and their dispersions. Kulkarni et.al. and Vijayakumar et al. studied experimentally the interaction between the naval ship exhaust and the funnel air wake within a setup wind tunnel [7-8]. In order to investigate the impacts on the exhaust dispersion, they implemented four different upper deck layouts, 2 different stack geometries and 2 different velocity ratios in the flow visualization tests. (See Equation (1) for the detailed definition of velocity ratio) As a conclusion of their study, they provide a number of conditions for flows over the forward stack and aft stack. The interactions of the exhaust plume with the ship structures in the close areas are likely to overestimate the downwash. Therefore, such full-scale design setups would be considered as conservative for the model tests.

Overcamp carried out an experimental study to figure out the scaling and downwash phenomena by implementing ten separate models [9]. He analysed the data of downwash sequence from these studies based on the theory developed by Tatom. There was compliance between Tatom's theory and the downwash occurrences. Accordingly, we can conclude that Tatom's theory could be implemented in constructing subcritical models for preventing possible downwash [10].

Lee and Zan conducted subscale experiments in wind tunnel [11]. They investigated the unsteady aerodynamic loads upon the fuselage of a rotorless helicopter in a ship air-wake. A coefficient for the unsteady aerodynamic load was defined from the curve fits for spectral of the collapsed and normalized power-spectral densities which were developed from the experiment results. Unsteady load coefficients for the side force, drag force and yawing moment were evaluated as a function of the speed and direction of the wind as well as of the position for fuselage. The ramifications of the collapsed and normalized powerspectral densities were analysed.

However for real world cases, modelling of every running/cruise conditions in wind tunnel experiments is not easy and economic. The modelling of the complex geometries and the flow analysis are now possible with the development of the computational fluid dynamics (CFD) technology. There are many CFD studies on the spread of the exhaust smoke of the ships in the literature. For example, the configuration of the funnels for the merchant ship and for the naval ships is rigorously investigated by Baham and McCallum [12]. They analysed the designing structures of the funnels of the surface ships. Jin et al. provided a numerical evaluation, to present plume dispersion of the exhausts for the stack and accommodation arrangements [13]. Kulkarni et al. studied the topside layouts of a frigate by using numerical techniques [14]. The results were presented for differing ratios of the speed and the directions of the wind with four super-structures. Kim et al. investigated the dispersion of exhaust gases and discussed the stack performance for different stack shapes [15]. Huang et al. studied the exhaust gas plumes for different ship motions using numerical methods and they presented the distribution of the temperature and concentration, buoyancy effects, flow zone and the effects of the velocity of the exhaust smoke [16]. Park et al. investigated the flow of the exhaust-gas from the ship's funnel, analytically [17]. In the studies of Ergin et al., Dobrucali and Ergin and Ergin and Dobrucali, the interaction of the exhaust smoke with the super-structure of a frigate is analysed [18-22]. The analysis was conducted for the exhaust gas with a variety of four yaw angles, velocities and the temperatures. The temperature contours, streamlines and concentrations of the exhaust smoke were evaluated and the results were contrasted with respect to the experiment data. The paper has showed that CFD is a practical and strong tool to study the interaction issues between the exhaust smoke and the ship super-structures. Recently, Scott et al. modelled the unsteady ship air wakes and analysed the interaction between air wakes and ship's exhaust [23]. The temperature and dispersion data of exhaust gases were collected to determine the effects on the helicopter operations. There is other analysis on the concentration of the flow over the ship super-structure and its impacts on the helicopter operations [24-36]. 
As can be seen from the literature review, there are many detailed numerical studies dealing with the exhaust smoke dispersion of ships, but only few experimental and analytical studies are available in the literature. This study develops further the analysis of the authors by flow visualization and analytical results on the exhaust gas dispersion from the generic frigate [18-22]. In the previous works of the author, the problem of the exhaust gas dispersion of frigate has been studied by using numerical techniques. As a result, this paper provides an original research.

The main point of the study is to analyse the exhaust gas dispersion of a generic frigate by flow visualization tests. The impacts of the efflux velocity for the forward and astern cruises of the frigate and the yaw angle on the exhaust gas dispersion are studied by flow visualization tests using a wind tunnel. For this purpose, 1/100 scaled generic frigate was built. Furthermore, an analytical study was conducted to obtain the plume trajectories. The outcomes of the study reveal that exhaust smoke dispersion is impacted significantly by the velocity of the efflux and yaw angle. When we increase the velocity ratio from $\mathrm{K}=0.2$ to $\mathrm{K}=\infty$, the momentum of the exhaust gases from the stack and the plume height increase. With reference to the impact of the velocity ratio on the dispersion of the exhaust smoke, there is a smoke nuisance issue for the lower velocity ratios like $\mathrm{K}=0.2$. The results showed that the plume was directed towards the helicopter deck at the back end of the superstructure when the yaw angles are higher than $10^{\circ}$. Namely, there is a downwash problem for the yaw angles higher than $10^{\circ}$. Finally, the experimental results are compared with the analytical solutions for three different velocity ratios, $\mathrm{K}=0.2, \mathrm{~K}=0.4$ and $\mathrm{K}=0.8$. The general agreement between the experimental and analytical results is seen to be in compliance.

\section{Physical Model}

The 1/100 scaled generic frigate with the platform for helicopters on the aft of the ship was built and employed during the experimental study. As can be seen from Fig. 1 , the main mast, electronics, bridge, radar dome and Sea Zenit weapon system on the upper deck are all set up. The reason for choosing this type of frigate is the fact that the ship is constructed with a helicopter platform as well as electronic and weapon systems. They are prone to the impacts due to the exhaust gases. The main specifications of the generic frigate are provided in Table 1.

Table 1 Main specifications of the generic frigate

\begin{tabular}{|l|c|}
\hline \multicolumn{2}{|c|}{ Specifications of Frigate } \\
\hline Length (m) & 110 \\
\hline Breadth (m) & 14.2 \\
\hline Draught (m) & 4.1 \\
\hline Displacement (ton) & 2414 \\
\hline Main engine & 4 Diesel engines \\
\hline Propulsion System & CODAD \\
\hline Power (kW) & 7400 \\
\hline Speed (knot) & 28 \\
\hline
\end{tabular}

Source: Author

The frigate has a helicopter platform with the capacity of landing/departure of the helicopters such as SH-60 (Seahawk). The frigate model scaled 1/100 has been built and employed for the experimental study. The generic frigate model and its upper deck layout are shown in Fig. 1.

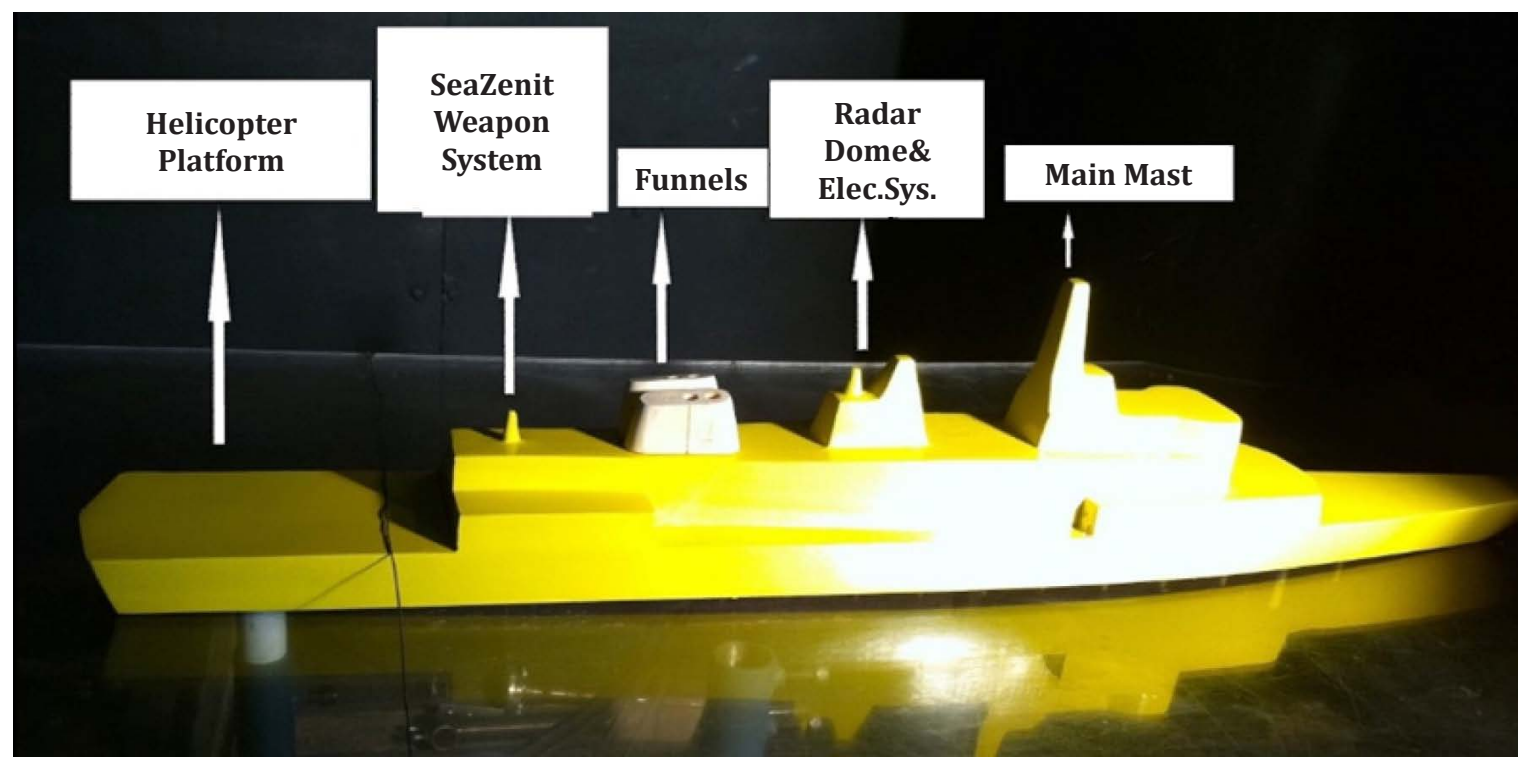

Fig. 1 1/100 scaled model of the frigate 


\section{Experimental Procedure}

The blown type wind tunnel was chosen for the visualization tests of the flow (see, Fig. 2). It consists of a chamber, a diffuser and a section of $0.80 \times 0.80 \mathrm{~m}^{2}$ with a length of 2.0 $\mathrm{m}$. The maximum speed in the wind tunnel is $15.0 \mathrm{~m} / \mathrm{s}$.

The smoke at the temperature of the ambient was provided through the stack of the model to show the exhaust smoke of the frigate. During the flow visualization tests, the smoke was produced by using a smoke generator, which was Safex Nebelsonde NS2 type. There was a standard Pitot tube inserted into the wind tunnel to measure the free stream velocity in the wind tunnel. Still photographs and videos of the smoke flowing from the stacks were taken by the SONY Handy Cam 420 . The camera was placed on the tripod outside the wind tunnel.

The blockage effects were considered before the wind tunnel tests performed. This effect is calculated with the ratio of the cross-section for the scaled model to the crosssection of the wind tunnel. This ratio should be between $1.0 \%$ and $10.0 \%$ [37]. For this experimental study, the results showed that the ratios were calculated as $2.8 \%, 4.7 \%$ and $7.2 \%$ for the yaw angles $\Psi=0^{\circ}, 10^{\circ}$ and $20^{\circ}$, respectively. Therefore, the dimension of the wind tunnel did not affect the flow visualization tests, adversely. The uncertainties of the experiment which cover the deviation due to measurement and calculation errors are found to be between $10 \%$ to $15 \%$.

The impacts of the velocity ratio and yaw angle on the exhaust smoke dispersion of the frigate were analysed in this paper. The velocity ratio is defined as follows:

$\operatorname{VelocityRatio}(K) \equiv \frac{V_{s}}{V_{w}}$

In equation (1), $V_{s}$ is the exit velocity of exhaust gas from the stack and $V_{w}$ is the inlet velocity of the wind tunnel. The smoke was produced in the smoke generator with a constant velocity as $V_{s}=2.0 \mathrm{~m} / \mathrm{s}$. The inlet velocity of the wind tunnel was changed from $V_{w}=0 \mathrm{~m} / \mathrm{s}$ to $15.0 \mathrm{~m} / \mathrm{s}$.

The yaw angle, $\Psi$ is set as the angle between the direction of the relative velocity of the ship and the direction of the ship, see Fig. 3. In the wind tunnel tests, the direction of $1 / 100$ scaled frigate model was changed from $\Psi=0^{\circ}$ to $\Psi=20^{\circ}$ accordingly.

In this work, the impact of four varying velocity ratios $(\mathrm{K}=0.2,0.4,0.8$ and $\infty$ (ship stops)) on the diffusion of the exhaust gases was analysed, please check Cases 1 to 4 in Table 2. The effect of backward cruising of the warship on the exhaust dispersion was studied for 2 velocity ratios (Cases 2 and 3). The effects of three yaw angles, $\Psi=0^{\circ}, 10^{\circ}$ and $20^{\circ}$ on the exhaust dissipation were studied (see, Case 3,5 and 6 in Table 2).

Table 2 summarizes the parameters for the cases, Cases 1 to 6 .

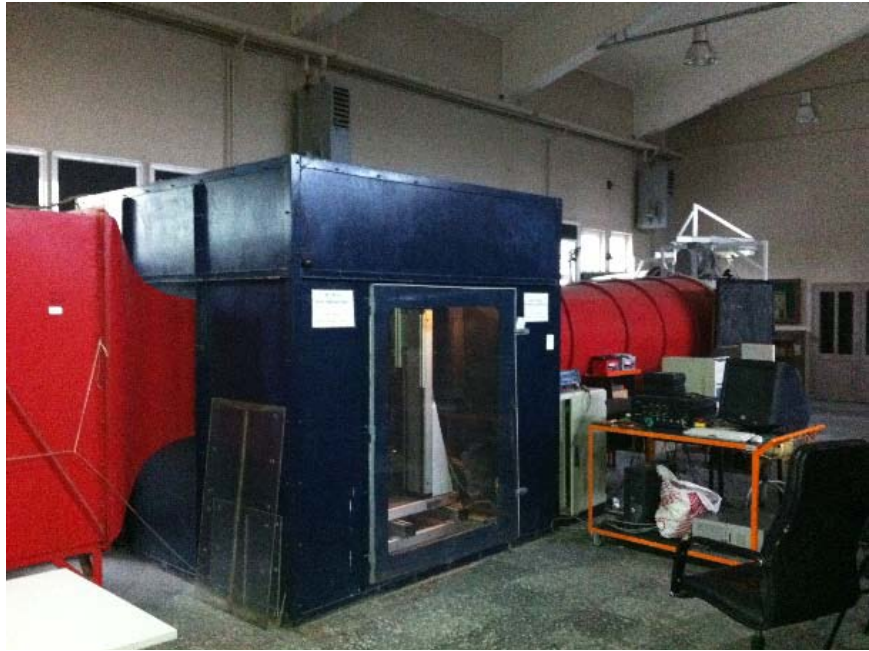

a) Front view

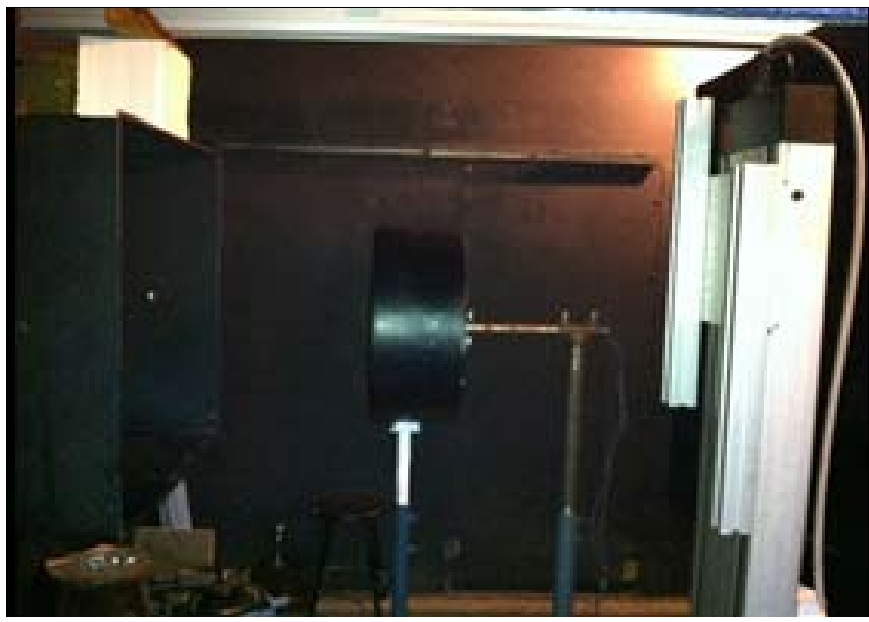

b) Inside view

Fig. 2 Wind tunnel

Source: Author

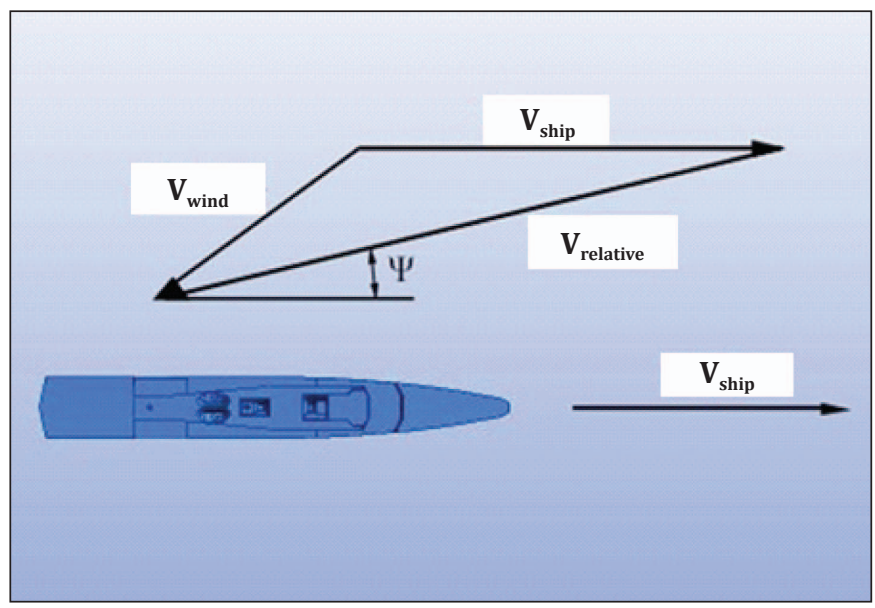

Fig. 3 The yaw angle ( $\Psi$ ) 
Table 2 Parameters of the cases for the experimental investigation

\begin{tabular}{|c|c|c|c|c|}
\cline { 2 - 5 } \multicolumn{1}{c|}{} & $\begin{array}{c}\text { Inlet velocity of the wind tunnel } \\
(\mathbf{m} / \mathbf{s})\end{array}$ & $\begin{array}{c}\text { Exit velocity of the exhaust } \\
(\mathbf{m} / \mathbf{s})\end{array}$ & $\begin{array}{c}\text { Velocity ratio, } \\
\mathbf{K}\end{array}$ & $\begin{array}{c}\text { Yaw angle, } \\
\mathbf{\Psi}\left({ }^{\circ}\right)\end{array}$ \\
\hline Case 1 & 10.0 & 2.0 & 0.2 & 0 \\
\hline Case 2 & 5.0 & 2.0 & 0.4 & 0.8 \\
\hline Case 3 & 2.5 & 2.0 & 0 \\
\hline Case 4 & 0.0 & 2.0 & 0 \\
\hline Case 5 & 2.5 & 2.0 & 0.8 & 0 \\
\hline Case 6 & 2.5 & 2.0 & 10 & 0.8 \\
\hline
\end{tabular}

Source: Author

\section{Analytical Calculation of the Plume Trajectory}

The hot exhaust plume from a ship funnel is buoyant and this buoyancy affects the trajectory of the exhaust plume [12]. The effects of buoyancy force increase at high velocity ratios and become more important. Generally, high velocity ratios are not the critical design condition since the exhaust gases are in contact with wind speed with $90^{\circ}$ and they don't significantly alter its direction. Therefore, the exhaust gases and ambient wind momentum define the dispersion of exhaust gases at low velocity ratios. The trajectory of exhaust gases can be obtained by using the analytical model derived by Baham and McCallum [12].

If the wind speed $\left(V_{w}\right)$ is constant and $\mathrm{dp} / \mathrm{dy}=0$, then for $\mathrm{X}<\mathrm{X}$, the trajectory of the plume, $\mathrm{y}$ can be calculated as:

$\frac{y}{R_{S}}=\frac{\left(V_{S} / V_{w}\right)\left(X / R_{S}\right)^{1 / 2}}{\left(\beta+\alpha V_{S} / V_{w}\right)^{1 / 2}}$

In Equation (2), $\mathrm{X}_{\mathrm{c}}$ can be obtained as follows:

$X_{c}=\left(\frac{2 \beta^{2}}{3}\right)^{2}\left(\frac{V_{s} / V_{w}}{\beta+\alpha V_{S} / V_{w}}\right)^{3} \frac{L_{m}^{3}}{L_{b}^{2}}$

For $\mathrm{X}>\mathrm{X}_{\mathrm{c}^{\prime}}$ the trajectory of the plume, $\mathrm{y}$ can be defined as:

$y=\left(\frac{3}{2 \beta^{2}}\right)^{1 / 3} L_{b}^{1 / 3} X^{2 / 3}$

where $V_{s}$ is the exit velocity of the exhaust, $V_{w}$ is the inlet velocity of the wind tunnel, $R$ is the radius of the funnel and $\mathrm{X}$ is the horizontal distance from the midpoint of the funnel. $\alpha=0.15$, though being universal constant, $\beta$ is not a constant and its value is between 0.8 and 1.2 depending on the velocity ratio and Fr. In this study, $\beta$ was taken as 1.2.

$L_{m}$ and $L_{b}$ in Equation (3) are respectively the momentum length scale and the buoyancy length scale and they can be obtained as follows:

$L_{m}=R_{S}\left(\frac{V_{s}}{V_{w}}\right)$

$L_{b}=\left(\frac{F_{S}}{V_{w}^{3}}\right)$ where $\mathrm{F}_{\mathrm{s}}$ can be obtained as:

$F_{S}=V_{S} R_{S}^{2} \delta g$

In this equation, $\mathrm{g}$ is the gravity acceleration and $\delta$ is the ratio of the buoyancy force which is defined as:

$\delta=\frac{\rho_{\infty}-\rho_{S}}{\rho_{\infty}} \equiv \frac{T_{S}-T_{\infty}}{T_{S}}$

In this study, the exhaust exit temperature, $\mathrm{T}_{\mathrm{s}}$ and the ambient temperature, $\mathrm{T}_{\infty}$ were assumed constant as $21.6^{\circ} \mathrm{C}$ and $15^{\circ} \mathrm{C}$, respectively. Using these values, the ratio of the buoyancy force, $\delta$ was calculated as 0.305 . The radius of the funnel, $R_{s}$ is taken as $0.011 \mathrm{~m}$.

For the $1 / 100$ scaled model for the generic warship, the trajectories of the exhaust smoke from the centre of the funnel exit are calculated for 3 various velocity ratios, $\mathrm{K}=0.2, \mathrm{~K}=0.4$ and $\mathrm{K}=0.8$. The results of the analytical modelling are presented and discussed in Section 5.3.

\section{Results and Discussion}

\subsection{The effects of velocity ratios on the exhaust diffusion}

The effects of four varying velocity ratios $(\mathrm{K}=0.2,0.4$, 0.8 and $\infty$ ) on the exhaust diffusion of the generic warship was given in Figs. 4a-d. In order to change the velocity ratio, exit velocity in the stack outlet was kept constant as $2.0 \mathrm{~m} / \mathrm{s}$ and the inlet velocity of the wind tunnel was changed from 0 to $10.0 \mathrm{~m} / \mathrm{s}$. Fig. 4 shows the results for the yaw angle, $\Psi=0^{0}$ and starboard port inclined stack geometry.

As seen from Fig. 4 that the momentum of the exhaust gas at stack arises when the velocity ratio goes up from $\mathrm{K}=0.2$ to $\mathrm{K}=\infty$. As a consequence of that phenomena, the plume height of smoke goes up as the velocity ratio increases. As can be seen clearly from the Fig. 4a, the downwash problem occurs in the case with $\mathrm{K}=0.2$. Therefore, the operation of the helicopter may be influenced negatively for this case.

The effects of velocity ratio on the exhaust diffusion for the backward cruising position are given in Figs. 5a-b for 


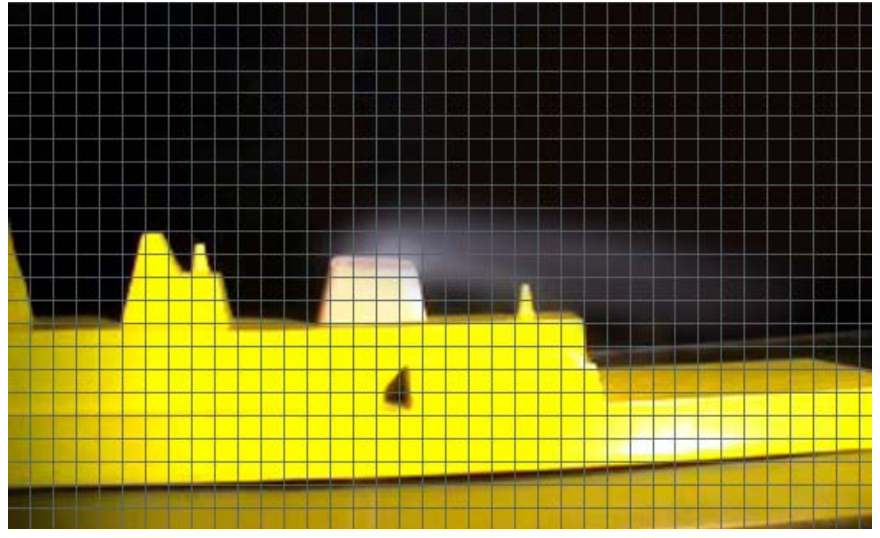

a)

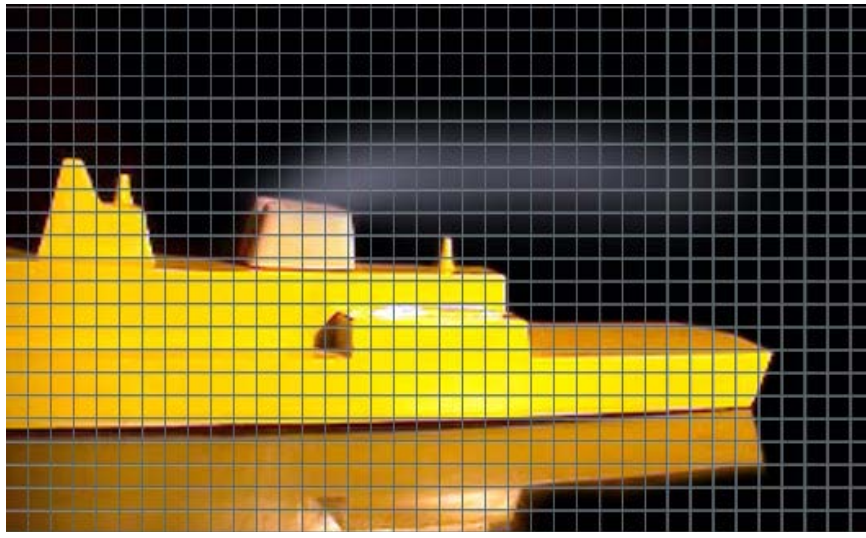

c)

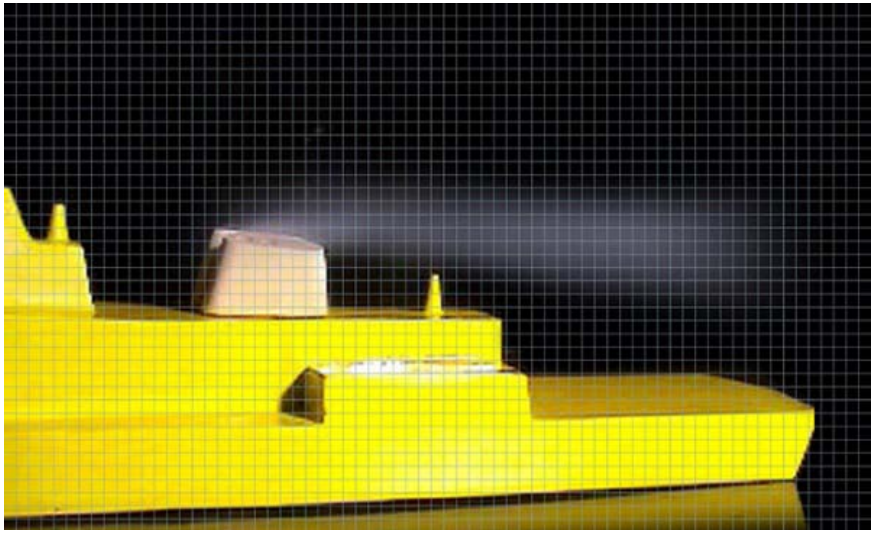

b)

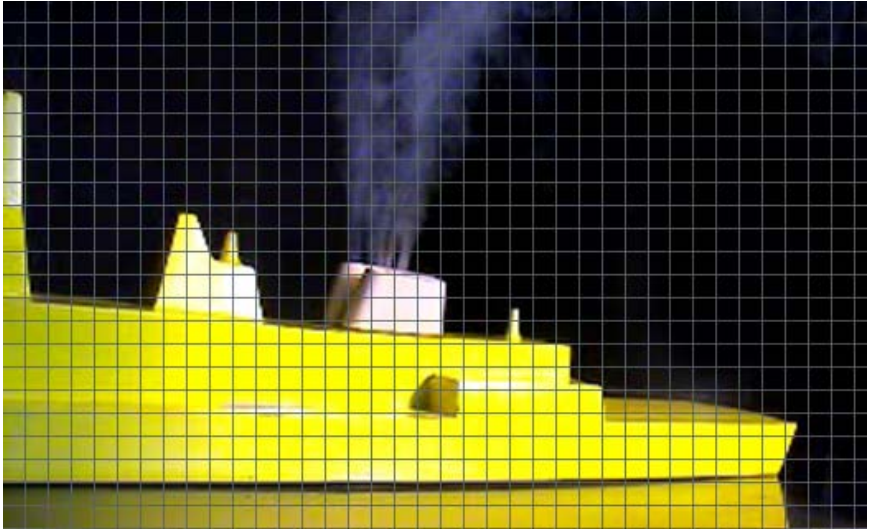

d)

Fig. 4 The effects of velocity ratio on the exhaust dispersion for a) Case 1, b) Case 2 and c) Case 3 and d) Case 4. Source: Author

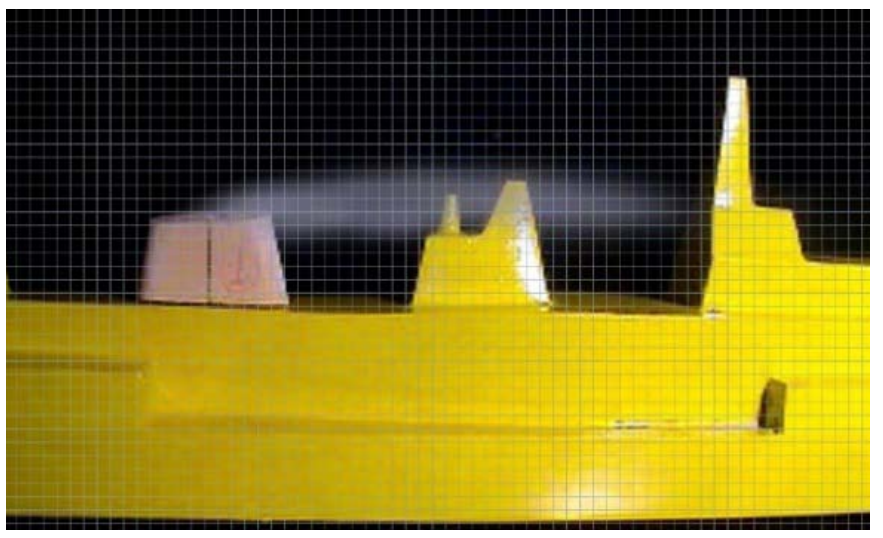

a)

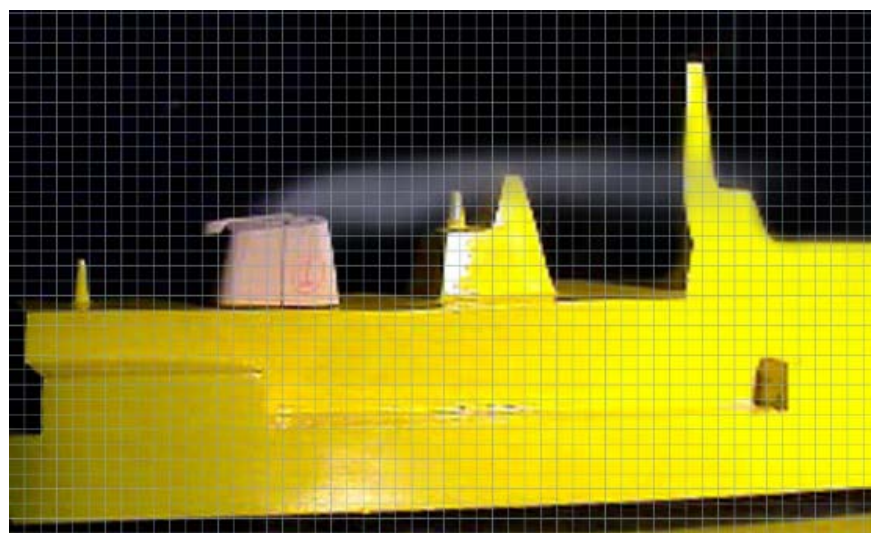

b)

Fig. 5 The effects of velocity ratio on the exhaust dispersion for backward cruising. a) Case 2 and b) Case 3.

Source: Author

the starboard-port inclined stack geometry. Fig. 5a demonstrates the consequences for the velocity ratio $\mathrm{K}=0.4$ (Case 2) and Fig. 5b for the velocity ratio $\mathrm{K}=0.8$ (Case 3 ). For both cases, the exhaust plume negatively influences the sensor and electronic devices on the main mast and radar dome. However, it may be said that the smoke nuisance problem may not be deemed as a concern because of the fact that the backward cruising takes very short time and also the temperature of exhaust are lower than that of the forward cruising condition. 


\subsection{The effect of yaw angle on the exhaust diffusion}

The effect of 3 varying yaw angles, $\Psi=0^{\circ}, 10^{\circ}$ and $20^{\circ}$ on the exhaust diffusion for the generic warship are given in Figs. 6a-c. The velocity ratio was kept constant as $\mathrm{K}=0.8$. Besides that, the direction of the bow of the ship was changed from $0^{\circ}$ to $20^{\circ}$ inside the wind tunnel. Fig. 6 presents the results for the starboard-port inclined stack geometry.

As shown in the Fig. 6, the plume is sent to the helicopter deck at the back end of the superstructure when

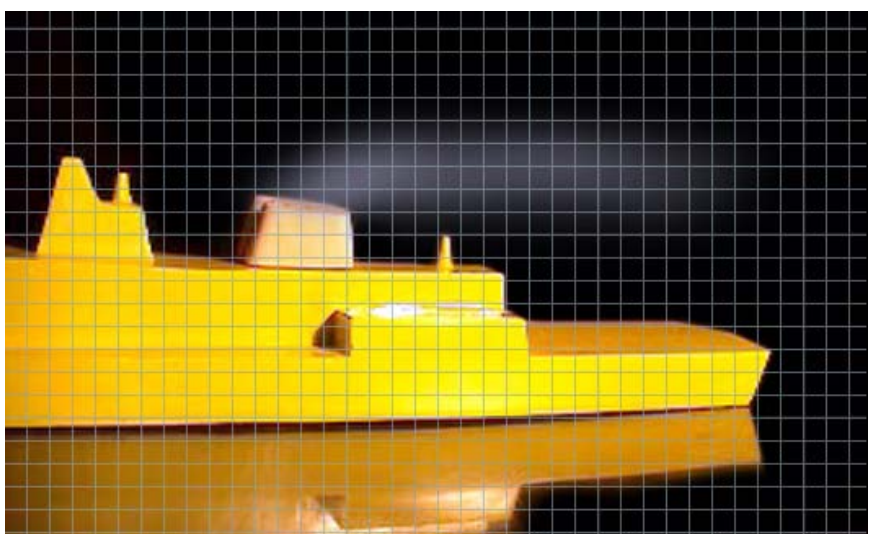

a)

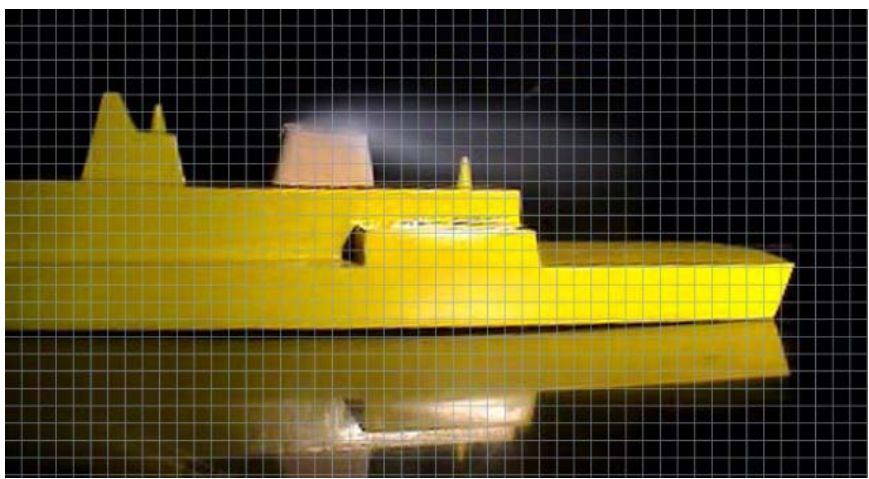

b)

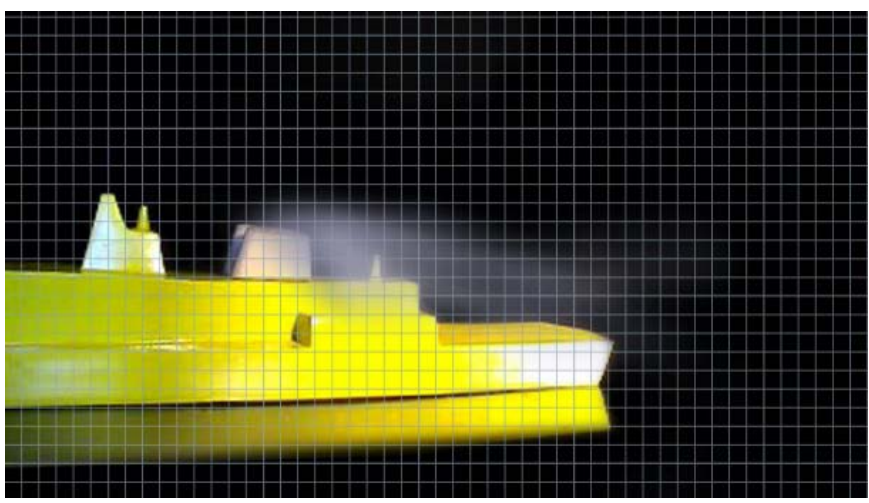

c)

Fig. 6 The effect of yaw angle on the exhaust diffusion for a) Case 3, b) Case 5 and c) Case 6. the angles of yaw are bigger than $10^{\circ}$. So, the exhaust gas cannot rise with the momentum and the buoyancy, and it can't depart from the turbulent area. Thus, the downwash phenomena takes place regarding the Case 6 with $\Psi=20^{\circ}$. All these findings suggest that exhaust gases negatively influence the human health, weapon and electronic systems. In order to avoid the smoke nuisance problem, some precautions can be taken to increase the momentum of the exhaust gases by using a vane.

\subsection{The analytical results for different velocity ratios}

The plume trajectories for 3 varying velocity ratios, $\mathrm{K}=0.2, \mathrm{~K}=0.4$ and $\mathrm{K}=0.8$ are calculated analytically and presented in Fig. 7. These results should be compared with the results presented for Cases 1, 2 and 3 in Fig. 4a-c. The plume trajectories are calculated from the centreline of the funnel exit.

As can be seen from Fig. 7, the momentum of the exhaust gases goes up as the velocity ratio arises from $\mathrm{K}=0.2$ to $\mathrm{K}=0.8$. Thus, the smoke plume height goes up as the velocity ratio increases. This phenomenon was also seen in the experimental results presented in Fig. 4a-c. However, the downwash problem obtained experimentally for the ratio of velocity $\mathrm{K}=0.2$ can't be seen clearly in the analytical results shown in Fig. 7. This is due to assumptions made in the analytical modelling. Therefore, the analytical results should be used carefully in the design of the exhaust stacks.

\section{Conclusions}

The effects of design parameters such as efflux velocity and angle of yaw on the exhaust smoke diffusion of the warship were studied by employing the flow visualization tests. The analytical study was also conducted to obtain the exhaust plume trajectories. The 1/100 scaled generic frigate with a helicopter deck on the aft was built and employed during the experimental study. For the flow visualization tests, the blown type wind tunnel including a settling chamber, a diffuser and a test section were used. A smoke generator was also used to produce the smoke.

The blockage effects were considered before the wind tunnel tests performed and the scale of the generic frigate was decided accordingly. Therefore, the dimensions of the wind tunnel did not affect the flow visualization tests, adversely. The uncertainty level of the experiments including measurements and computation deviations was found to be around $10 \%-15 \%$.

The findings demonstrate that exhaust plume diffusion is influenced at a significant level by the efflux velocity and yaw angle. When the velocity ratio goes up from $\mathrm{K}=0.2$ to $\mathrm{K}=\infty$, the momentum of the exit gas at stack and the plume height also arises. Looking at the effects of the velocity ratio on the exhaust gases diffusion, there is a plume nuisance problem for the low velocity ratios like $\mathrm{K}=0.2$. Therefore, the operation of the helicopter may be 


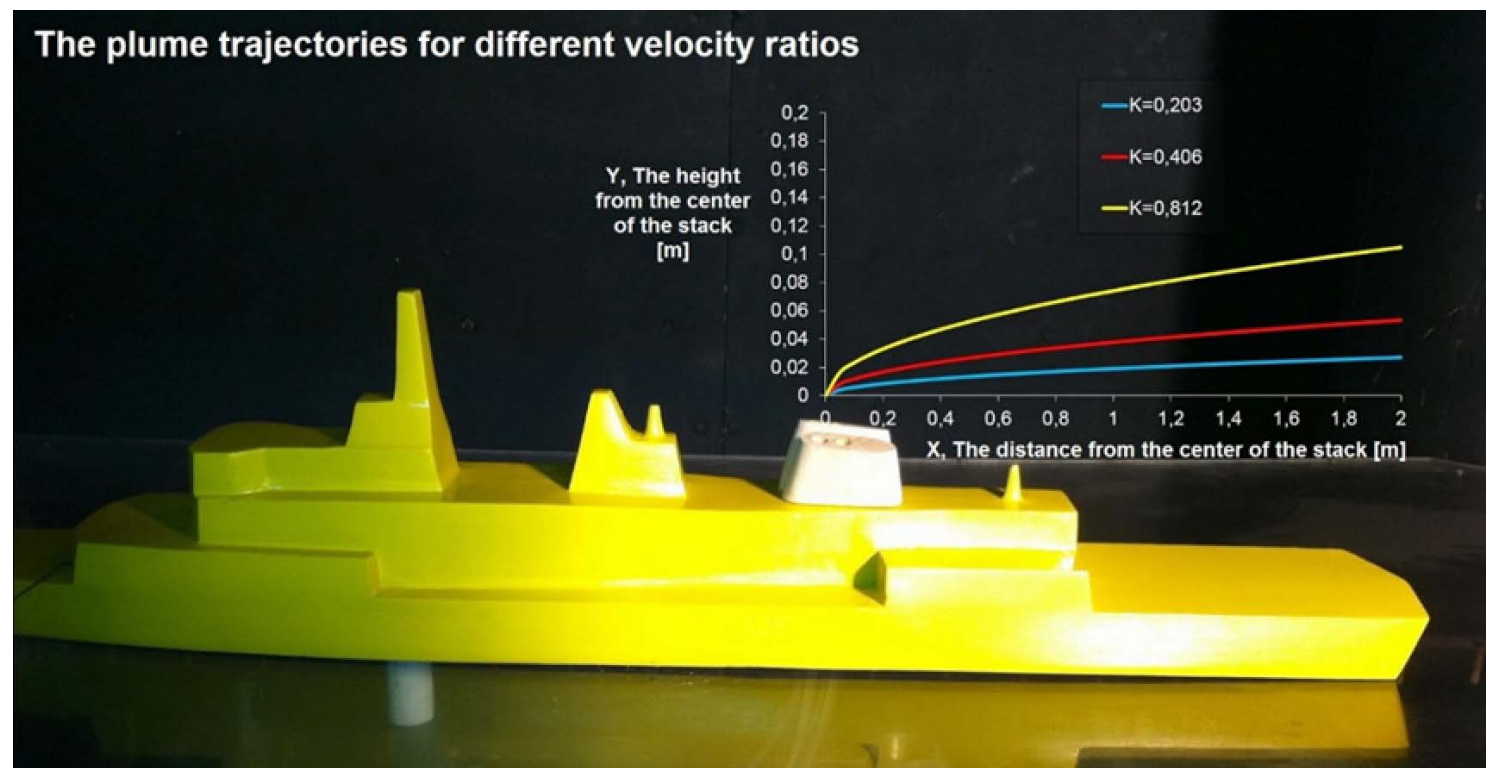

Fig. 7 The plume trajectories for different velocity ratios

Source: Author

influenced negatively for the case. The findings revealed that the plume is directed to the deck at the back end of the superstructure for the yaw angles higher than $10^{\circ}$. So, the exhaust gas cannot rise with the momentum and the buoyancy and it can't depart from the turbulent area in the superstructure. All these findings suggest that exhaust gases negatively influence the human health, weapon and electronic systems. The high stack exit velocity values and high stack heights may be used to increase the momentum and buoyancy of the exhaust gases and to avoid the downwash phenomena. The experimental results are compared with the analytical solutions for 3 different velocity ratios. It is also found that there is a good match between the experimental and analytical results.

The increase of exhaust gas at the stack is largely dependent on the momentum and buoyancy effects. The velocity constitutes the essential part of the momentum. On the other hand, the buoyancy effect takes place because of the differences in ambient air and exhaust gas temperatures. However, the buoyancy has a relatively smaller effect on the increase of exhaust gases as compared to effect of momentum. Additionally, the turbulence effect may also play an important role in the increase of exhaust gases. The buoyancy effect was not observed during the study. The exhaust emissions like $\mathrm{NO}_{\mathrm{X}}, \mathrm{SO}_{\mathrm{X}}, \mathrm{CO}_{2}, \mathrm{CO}, \mathrm{HC}$ and $\mathrm{PM}$ have adverse effects on the human health and environment. The smoke nuisance or downwash problem of the ship may lead to many negative effects like high temperature contaminations of electronic and warship sensors/equipment in the upper deck, interference of the exhaust gases with helicopter operations and also with engine intakes as well as the air conditioners of the ship. Furthermore, the stack design and the dissipation of exhaust gases have become important regarding the radar cross-section and infrared signature in line with the new developments on the military technology. Thus, in designing the ships, the true definition of the exhaust gas diffusion for various operational purposes is critically important in order not to experience downwash or smoke nuisance issues. The results of the study show that the flow visualization tests are very useful tool to obtain the correct dissipation of the exhaust gases and their interaction with the ship super-structure to avoid the downwash or smoke nuisance problems. Also, the findings of the flow visualization tests can be used to validate the computational models.

\section{Nomenclature}

Fr Froude Number

$g$ Gravity

$\mathrm{K}$ Velocity ratio

$L_{m}$ Momentum length scale

$L_{b} \quad$ Buoyancy length scale

$R_{s}$ Radius of the funnel

$\mathrm{T}_{\mathrm{s}}$ Exhaust exit temperature

$\mathrm{T}_{\infty}$ Ambient temperature

$V_{S}$ Exit velocity of exhaust gas from the stack

$V_{W}$ Inlet velocity of the wind tunnel, wind speed

$X$ Horizontal distance from the center of the funnel

$y \quad$ Trajectory of the plume

$\delta$ Ratio of the buoyancy force

$\Psi$ Yaw angle

\section{Acknowledgements}

Author would like to acknowledge and thank Scientific Research Projects Coordination Office (BAP) of Istanbul Technical University, Turkey for their financial support to carry out this study. 


\section{References}

[1] Nolan, R.W. (1946). Design of Stacks to Minimize Smoke Nuisance. Trans SNAME, Vol. 54, 42-82.

[2] Acker, H.G. (1952). Stack Design to Avoid Smoke Nuisance. Trans SNAME, Vol. 60, 566.

[3] Third, A.D. and Ower E. (1962). Funnel Design and Smoke Plume. Trans. Institute of Marine Engineers (London), Vol. 72, 245-272.

[4] Johns, M.K. and Healey, J.V. (1989). The Airwake of a DD 963 Class Destroyer. Naval Engineers Journal, ASNE, 36-42, doi. org/10.1111/j.1559-3584.1989.tb02184.x.

[5] Johns, M.K. (1988). Flow Visualization of the Airwake around a Model of a DD-963 Class Destroyer in a Simulated Atmospheric Boundary Layer. Master Thesis, Naval Postgraduate School.

[6] Harrell, J.P. (1977). Experimentally Determined Effects of Eductor Geometry on the Performance of Exhaust Gas Eductors For Gas Turbine Powered Ships. Master Thesis, Naval Postgraduate School.

[7] Kulkarni, P.R., Singh, S.N. and Seshadri, V. (2007). Parametric Studies of Exhaust Smoke - Superstructure Interaction on a Naval Ship Using CFD, Computer \& Fluids, 36, 794-816, doi. org/10.1016/j.compfluid.2006.07.001.

[8] Vijayakumar, R., Seshadri, V., Singh, S.N. and Kulkarni, PR. (2008). A Wind Tunnel Study on the Interaction of Hot Exhaust from the Funnel with the Superstructure of a Naval Ship. IEEE Sections Congress. 978-1-4244-2126.

[9] Overcamp, T.J. (2001). A Review of Conditions Leading to Downwash in Physical Modeling Experiments, Atmospheric Environment 35, 3503-3508, doi.org/10.1016/S13522310(01)00114-5.

[10] Tatom, F.B. (1986). Predictions of stack plume downwash. Journal of Fluids Engineering, 108, 379-382, doi. org/10.1115/1.3242591.

[11] Lee, R.G. and Zan, S.J. (2002). Wind Tunnel Testing to Determine Unsteady Loads on a Helicopter Fuselage in a Ship Airwake, ICAS 2002 Congress.

[12] Baham, G.J. and McCallum, D. (1977). Stack Design Technology for Naval and Merchant Ships, Sname Transaction, 85, 324-349.

[13] Jin, E., Yoon, J. and Kim, Y. (2001). A CFD-Based Parametric Study on the Smoke Behavior of a Typical Merchant Ship, Practical Design of Ships and Other Floating Structures, Vol. 1, 459-465, doi.org/10.1016/B978-008043950-1/50058-2.

[14] Kulkarni, P.R., Singh, S.N. and Seshadri, V. (2005). Flow Visualization Studies of exhaust Smoke-Superstructure Interaction on Naval Ships, Naval Engineering Journal, Vol. 117, 41-56, doi.org/10.1111/j.1559-3584.2005.tb00320.x.

[15] Kim, J.H., Park, S.M., Cha, H. and Seol, S.S. (2008). Numerical Research on Establishing Optimum Design Criterion of Ship's Funnel, ASME International Mechanical Engineering Congress and Exposition.

[16] Huang, J., Carrica1, P.M. and Stern, F. (2010). A Method to Compute Ship Exhaust Plumes with Waves and Wind, International Journal for Numerical Methods in Fluids, 68(2), 160-180, doi.org/10.1002/fld.2499.

[17] Park, S., Heo, J., Yu, B.S. and Rhee, S.H. (2011). Computational Analysis of Ship's Exhaust-Gas Flow and its Application for Antenna Location, Applied Thermal Engineering, Vol. 31, 1689-1702, doi.org/10.1016/j.applthermaleng.2011.02.011.
[18] Ergin, S., Parali, Y. and Dobrucali, E. (2011). A numerical investigation of exhaust smoke-superstructure interaction on a naval ship. Proc. of IMAM 2011, Sustainable Maritime Transportation and Exploitation of Sea Resource, Genoa, Italy, 109-115.

[19] Dobrucali, E. and Ergin, S. (2012). A study of exhaust smoke dispersion for a generic frigate. GMO Journal of Ship and Marine Technology, 192, 16-22.

[20] Dobrucali, E. and Ergin, S. (2013). Exhaust smoke dispersion for a generic frigate: Computational modelling and comparisons with experiments. IMAM 2013, Developments in Maritime Transportation and Exploitation of Sea Resources, Coruna, Spain, 811-817.

[21] Dobrucali E., Ergin S. (2017). An investigation of exhaust smoke dispersion for a generic frigate by Numerical analysis and experiment", Proceedings of the Institution of Mechanical Engineers, Part M: Journal of Engineering for the Maritime Environment, 147509021774224, doi: $10.1177 / 1475090217742240$.

[22] Ergin, S. and Dobrucali, E. (2014). Numerical Modeling of Exhaust Smoke Dispersion for a Generic Frigate and Comparisons with Experiments, Journal of Marine Science Application. 13: 206-211, doi.org/10.1007/s11804-0141246-x.

[23] Scott, P., White, M. and Owen, I. (2015). Unsteady CFD Modelling of Ship Engine Exhaust Gases and over-deck air Temperatures, and the Implications for Maritime Helicopter Operations, American Helicopter Society International (AHS) Annual Forum, Virginia, USA, 1-9.

[24] Geder, J., Ramamurti, R. and Sandberg, W.C. (2008). Ship Airwake Correlation Analysis for the San Antonio Class Transport Dock Vessel, Naval Research Laboratory Memorandum Report, NRL/MR/6410--08-9127.

[25] Landsberg, A., Sandberg, W.C., Young, T.R., Boris, J.P. (1996). DDG 51 Flt IIA Airwake study Part-2: Hangar Interior Flow. Naval Research Laboratory Memorandum Report, 96-78-98.

[26] Landsberg, A.and Sandberg, W.C. (2000). DDG 51 Flight II Airwake study Part-3: Temperature field analysis for baseline and upgrade configurations. Naval Research Laboratory Memorandum Report, 6401-00-8432.

[27] Nacakli, Y. (2010). Analysis of Helicopter Downwash/ Frigate Air wake Interaction Using Statistically Designed Experiments. PhD Thesis, Old Dominion University.

[28] Reddy, K.R., Toffoletto, R. and Jones, K.R.W. (2000). Numerical Simulation of Ship Airwake, Computers \& Fluids, 29, pp 451-465, doi.org/10.1016/S0045-7930(99)00033-X.

[29] Sharma, A. and Long, L.N. (2001). Airwake Simulations on an LPD 17, 15th AIAA Computational Fluid Dynamics Conference, AIAA 2001-2589.

[30] Syms, G.F. (2007). Numerical Simulation of Frigate Airwakes, International Journal of Computational Fluid Dynamics, 18(2), 199-207, doi.org/10.1080/10618560310 001634159.

[31] Syms, G.F. (2008). Simulation of Simplified-Frigate Airwakes Using a Lattice-Boltzmann Method, Journal of Wind Engineering and Industrial Aerodynamics, 96, 1197-1206, doi.org/10.1016/j.jweia.2007.06.040.

[32] Tattersall, P., Albone, C.M., Soliman, M.M. and Allen, C.B. (1998). Prediction of Ship Air Wakes over Flight Decks using CFD, RTO AVT Symposium on "Fluid Dynamics Problems of Vehicles Operating near or in the Air-Sea Interface, RTO MP-15, Amsterdam, Paper 5. 
[33] Tai, T. C. (1998). Simulation and Analysis of LHD Ship Airwake by Navier-Stokes Method, RTO AVT Symposium on Fluid Dynamics Problems of Vehicles Operating near or in the Air-Sea Interface, RTO MP-15, 4.1-10.

[34] Wilkinson, C.H., Zan, S.J., Gilbert, N.E. and Funk, J.D. (1998). Modelling and Simulation of Ship Air Wake for Helicopter Operations-A Collaborative Venture, RTO AVT Symposium.

[35] Zan, S.J., Syms, G.F. and Cheney, B.T. (1998). Analysis of Patrol Frigate Air Wakes, RTO AVT Symposium on Fluid
Dynamics Problems of Vehicles Operating near or in the AirSea Interface. RTO MP-15, 7.1-14.

[36] Nisham, A., Terziev, M., Tezdogan, T., Beard, T., Incecik, A. (2021). Prediction of the aerodynamic behaviour of a fullscale naval ship in head waves using Detached Eddy Simulation, Ocean Engineering, Vol. 222, 108583, doi. org/10.1016/j.oceaneng.2021.108583.

[37] Kaykisizli, H. (2006). The Wind Tunnel and Flow Visualization Technics, Master Thesis, Istanbul Technical University. 